Behavior and Social Issues, 24, 23-38 (2015). (C) Ashley Greenwald, Kathryn Roose, \& Larry Williams. Readers of this article may copy it without the copyright owner's permission, if the author and publisher are acknowledged in the copy and the copy is used for educational, not-for-profit purposes. doi:

$10.5210 /$ bsi.v. $24 \mathrm{i} 0.5448$

\title{
Applied Behavior Analysis and Behavioral Medicine: HISTORY OF THE RELATIONSHIP AND OPPORTUNITIES FOR RENEWED COLLABORATION
}

\author{
Ashley Greenwald ${ }^{1}$ \\ Kathryn Roose \\ Larry Williams \\ University of Nevada, Reno
}

\begin{abstract}
Behavioral Medicine (BM) is an interdisciplinary field concerned with the development and integration of behavioral and biomedical sciences (Schwartz \& Weiss, 1978b). The interdisciplinary nature of the field poses barriers to researchers and practitioners interested in the field. While there are currently many disciplines that contribute to the field of behavioral medicine, this paper focuses exclusively on the relationships between the biological and psychological sciences, highlighting the theoretical similarities and differences. Our preliminary analysis of publications in each discipline revealed that while Applied Behavior Analysis (ABA) had early influences in behavioral medicine and many behavior scientists recommend the collaboration between $\mathrm{ABA}$ and $\mathrm{BM}$, the relationship between the two is tenuous. The roles of an applied behavior analyst and practitioner of behavioral medicine are largely the same, focused on the prevention and treatment of health conditions. These similarities provide excellent opportunity for collaborative work. The present theoretical analysis of BM examines contributions of ABA to BM and vice versa, discusses ABA's history and current role within the field $\mathrm{BM}$, and provides a rationale for the future collaboration between of behavior science and behavioral medicine.

KEYWORDS: medicine, behavioral medicine, behavior analysis interdisciplinary
\end{abstract}

Behavioral medicine is an interdisciplinary field that has been producing research and sharing ideas between biomedical and behavioral sciences for the past 40 years. Although scientists from various disciplines may define the field of behavioral medicine differently, the most current and formal definition of the field is, "...the interdisciplinary field concerned with the development and integration of sociocultural, psychosocial, behavioral, and biomedical knowledge relevant to health and illness and the application of this knowledge to disease prevention, health promotion, etiology, diagnosis, treatment, and rehabilitation," ("International Society of Behavioral Medicine," n.d.).

The development of the field of Behavioral Medicine is recent and stemmed from a clinical need for integrating psychology and medicine. The earliest evidence of BM is seen in the journal of Psychosomatic Medicine published in the late 1930s, with the scientific assumptions being that physical ailments were a result of genetic predispositions and personality (Agras, 2001). As

\footnotetext{
${ }^{1}$ The first author may be contacted at agreenwald@unr.edu
} 
psychological research stemming from psychosomatic medicine moved away from psychoanalytic theory and back to the laboratory, more intervention research began being conducted, contributing to the development of a scientific study of behavioral medicine (Agras, 1982). Furthermore, the realization that medical ailments were a result of behavioral patterns (e.g., obesity resulting from inactivity and the overconsumption of food) catalyzed the development of the field. The first laboratory to study behavioral medicine was created at Stanford in 1975 and was overseen by Agras and his colleagues. At the time, procedures from the experimental analysis of behavior were being used, however the main theory influencing their work came from cognitive psychology, largely influenced by Bandura's Social Learning Theory (Agras, 2001).

The Yale Conference on Behavioral Medicine provided for the formal launch of the field in 1977 (Schwartz \& Weiss, 1978b). There was a need for interdisciplinary work with regard to a behavioral approach to the treatment and prevention of diseases, and the lack of a definition explaining the subject matter of this field was inhibiting research funding. The conference brought together behavioral and biomedical scientists to outline the emerging field of behavioral medicine. It was deemed most appropriate that behavioral medicine would be defined as a field, as opposed to a science, to emphasize the interdisciplinary nature of the subject matter. Four additional outcomes resulted from the conference: (1) a definition of behavioral medicine; (2) the content and sub areas to be included and excluded from the field; (3) a quality outlet for publication in the new field; and (4) the formation of the Society of Behavioral Medicine (Schwartz \& Weiss, 1978b).

The definition of behavioral medicine was revised several times to be inclusive of both biological and psychological sciences. Areas for inclusion were initially sociocultural influences, psychosocial factors, health and illness behaviors, cognitive determinants, diagnostic techniques, pain, treatment adherence, behavioral treatment, rehabilitation and prevention. Areas that were initially excluded from the field of behavioral medicine included mental illness, substance abuse, mental retardation and social welfare programs (Schwartz \& Weiss, 1978b). Schwartz and Weiss (1978a) commented that the exclusionary criteria were removed from the initial conception of the definition, and the specifics regarding physical disorders were removed in favor of an emphasis on development and integration of behavioral and biomedical sciences. Some of the fields that currently contribute to behavioral medicine include epidemiology, anthropology, sociology, psychology, physiology, pharmacology, nutrition, neuroanatomy, endocrinology and immunology ("Society of Behavioral Medicine," n.d.).

The Society of Behavioral Medicine (SBM), founded in 1978, identifies itself as a multidisciplinary organization dedicated to collaboration on research, public policy, prevention, treatment, and promotion of health ("Society of Behavioral Medicine," n.d.). In keeping with the theme of the Yale Conference (Schwartz \& Weiss, 1978b), the Society of Behavioral Medicine promotes the visionary statement that, "The whole is greater than the sum of its parts," ("Society of Behavioral Medicine," n.d.) meaning that multiple disciplines working together will provide new perspectives on the management of human behavior as it pertains to the treatment and prevention of health related conditions. The mission of the SBM is to bring together researchers and clinicians in the behavioral and biomedical sciences for collaboration and information exchange, to bring behavioral medicine to the attention of policy makers, and to gain resources to promote their vision statement, "Better health through behavior change," ("Society of Behavioral Medicine," n.d.). 
Whereas there are many unique sciences that contribute to the field of behavioral medicine, this paper will focus on the relationship between Behavioral Medicine (BM) and Applied Behavior Analysis (ABA). The purpose of this paper is to examine the relationships between the biomedical and behavioral sciences that make up the field of $\mathrm{BM}$, discuss the contributions of ABA to BM, examine ABA's history and current role within the field of BM, and provide a rationale for the future collaboration between $\mathrm{ABA}$ and $\mathrm{BM}$.

\section{Biology vs. Psychology}

Behavioral medicine is a unique field that lies within the convergence of the biomedical and behavioral sciences. In order to understand the contributions of each field to Behavioral Medicine, a brief history of the intersection of biology and psychology, particularly with regard to behavior science, is necessary. For the purposes of this analysis, we will consider that behavior analysis and other behavioral sciences will be considered psychology, whereas biomedicine and various medical sciences will be considered within the category of biology.

Behavior analysts recognize biological processes but do not necessarily rely upon them in their analysis (e.g., Skinner, 1976). Kantor (1982) explained that psychological events, such as thoughts and behaviors, cannot occur in the absence of the biological organism and that a biological change (e.g., disease) in the organism may affect the organism's psychological conduct. There are several major biological phenomena that should be considered in an analysis of psychological behavior: evolution, physiology, maturation, and ecology (Kantor, 1982). An organism must have certain biological features to engage in complex human behavior. The evolutionary differences between two organisms of the same species or a structural change to an organism (e.g., losing a limb) may limit the behaviors that the organism is physically able to engage in. Physiological functions of the organism may also limit the possibility of psychological behavior given the role of physiological function in psychological behavior. For example, digestion, respiration, and hormone production will all influence psychological action. Of course the organism is also limited by its maturation, or stage of development, whereby very young organisms or older organisms may be limited in their psychological actions by their current state of growth or development. Finally, ecology, although related to the environment and not necessarily the physical state of the biological organism, is recognized by biologists as having an influence on both biological and psychological factors, as the organism is not its own entity, but rather a member of its ecosystem, and particular attention should be paid to available resources, shelter and other ecological variables (Kantor, 1982).

Even though a biological change can influence behavior, Kantor (1982) asserted that from an analytical perspective, it is still necessary to preserve the identity of each separate field, in order to avoid the common misperception that psychological behaviors are functions of biological structures. Instead of assuming a causal relationship in that biological factors are the cause of psychological behaviors, we must instead understand that biology is an essential factor in behavior, but not causal (Kantor, 1982). Especially in relation to medicine, the greatest shortcoming of this misconception is that psychological behaviors are analyzed often exclusively from a biological or morphological development and little or no consideration is given toward psychological factors, such as the role of stimulus objects or environmental situations. As an example in the medical field, a neurologist who is treating a patient for bizarre or erratic behavior may conclude that the psychological behavior is caused exclusively by a morphology in neurons or a deficit or excess of neurotransmitters and may prescribe a regimen of psychotropic 
GREENWALD, ROOSE, \& WILLIAMS

\begin{tabular}{|l|l|l|}
\hline & $\begin{array}{l}\text { Biological } \\
\text { Treatment }\end{array}$ & $\begin{array}{l}\text { Psychological } \\
\text { Treatment }\end{array}$ \\
\hline $\begin{array}{l}\text { Biological } \\
\text { Condition }\end{array}$ & Medicine & Behavioral Medicine \\
\hline $\begin{array}{l}\text { Psychological } \\
\text { Condition }\end{array}$ & Psychiatry & $\begin{array}{l}\text { Psychology/Applied } \\
\text { Behavior Analysis }\end{array}$ \\
\hline
\end{tabular}

Figure 1. Disciplines identified based on both the biological and behavioral conditions of the body and treatment approaches.

medications without consideration of modification of the environmental contingencies to which the organism is subject.

In light of the interdisciplinary nature of behavioral medicine and the precautions suggested by Kantor, the authors offer a distinction between contributing fields. The present analysis will categorize the circumstances of the body into biological or psychological conditions, where biological conditions of the body are defined as processes at the physiological level and psychological conditions of the body involve behavioral processes that are influenced by the external environment. Within this intersection of biology and psychology, treatment can also be categorized. A biological or medical approach to treatment typically includes use of pharmaceuticals and surgery, thereby altering the physical body in some way; a psychological treatment approach typically includes manipulation of environmental variables or a particular type of talk therapy or counseling, which would also be considered a manipulation of environmental variables. Research and practice in behavioral medicine falls somewhere between the two sciences, typically including a biological condition of the body and a psychological treatment approach. To clarify, this analysis suggests that a biological treatment of a biological condition is medicine, a psychological treatment of a psychological condition is psychology, a biological treatment of a psychological condition is referred to as psychiatry, and finally a psychological treatment of a biological condition would be explored by the field of behavioral medicine (see Figure 1). This analysis, pinpointing the junction of the biological and psychological sciences with relation to behavioral medicine, paves a path for a definition of behavioral medicine from behavior analysis.

From the behavior analytic perspective, behavioral medicine is a treatment approach that occurs in response to a disturbance of the biological body but also a disturbance of the physical body's interaction with the environment that has biological implications for the organism. In this paradigm, there are both biological and behavioral components to consider. With regard to Kantor's warnings, it is imperative that scientists and clinicians in behavioral medicine maintain the integrity of both the biological and behavioral components, thereby preventing the common assumption that behaviors are exclusively functions of altered biological conditions. Therefore, in a true behavior analytic approach to behavioral medicine, one must include an environmental analysis and manipulation that will alter the behavior of the organism, resulting in biological or physiological changes in the organism. 


\section{The Relationship between Applied Behavior Analysis and Behavioral Medicine}

Applied behavior analysis and medicine in general are complementary in their goals, but differ in their approaches to treatment. ABA focuses primarily on assessment and intervention of behaviors targeted for reduction or acquisition with a primary scientific principle being that behavior is modified by its consequences. The role of the practitioner of ABA is largely to promote the treatment of health-related conditions through the use of environmental contingency management (Cooper, Heron, \& Heward, 2007). Medicine is a science that is fundamentally concerned with the practice of maintaining the health of the body, often involving use of pharmaceuticals or surgical procedures to alter the body in some way. Despite the similar goals and the many contributions of behavior analysis to medical conditions (e.g., Friman \& Piazza, 2011), medical practitioners rarely use behavioral treatments for a variety of reasons: (1) a lack of understanding of the field, (2) a lack of understanding of its methodologies, and (3) a view of behavior analysts as not recognizing emotional factors, which are widely accepted as contributors to medical conditions (Blum \& Friman, 2000).

Behavioral medicine seems to be the ideal avenue for behavior analysts to contribute to the field of medicine, however the evidence for contributions of ABA to the field of BM is currently hard to discriminate. In 2013, the Encyclopedia of Behavioral Medicine (Gellman \& Turner, 2013) compiled much of the research, theory and practice within the field. The vast compilation of information includes short entries from various disciplines on diseases, theories, biographies, and research. The information on behavior science is very limited with the only entries being: Behavior Change, Behavior Change Techniques, Behavior Modification and Operant Conditioning. These entries total about 10 pages of information in a conglomeration of information spanning more than 2,000 pages. Therefore less than $0.5 \%$ of the information published in the Encyclopedia is directly related to behavior analysis and its principles. Moreover, a brief and informal review of the recent research published in the Journal of Applied Behavior Analysis and the Journal of Behavioral Medicine also shows a disconnect between topics studied in behavioral medicine and behavior analysis, despite the similarity in each journals' proposed goals and interests. For example, when the first 5 years and last 5 years of JBM were compared to the same years of publications in JABA, a topics analysis found similar topics studied during the first 5 years, with divergence in the last 5 years. During the years 20092013, upwards of 200 articles (almost half of all publications) in JABA were specific to autism whereas there were only 3 articles mentioning autism in JBM.

Conference activities are another avenue for gathering information on the relationship, or lack thereof, between ABA and BM. The Special Interest Group (SIG) on Behavioral Medicine within the Association for Behavior Analysis International (ABAI) is advertised as "a place for individuals interested in clinical applications to health-related problems and social concerns," and includes references to the areas of self-injury, feeding disorders, sleep problems, obesity, pain, smoking cessation and biofeedback ("Association for Behavior Analysis International," n.d.). However, practitioners presenting at the ABAI conference seldom identify these areas of research as being within the realm of behavioral medicine. In 2007, a study that analyzed the trends in presentations at the annual conference of the Association for Behavior Analysis International (ABAI) from the years 1980-2007 concluded that during the years 1980-1991, behavioral medicine had its own track and code at the ABAI conference. Beginning in 1992, the behavioral medicine track was no longer exclusive. During the years in which behavioral medicine did have its own track at the ABAI convention, the number of presentations on the 
subject ranged from 8 to 29, with a mean of 18 presentations per year (Kangas \& Vaidya, 2007). Currently, there is a conference track at ABAI titled Clinical and Behavioral Medicine, however very few of the presentations are actually behavioral medicine (per our definition), with the focus instead being more on clinical psychology. With the exception of ABAI's Behavioral Medicine SIG, there is very little evidence of a current formal relationship between applied behavior analysis and behavioral medicine.

As a demonstration of the contributions that behavior analysts can make to behavioral medicine, research conducted by behavior scientists in pediatrics has proven to provide complementary contributions to the assessment of common behavior problems as well as the development and evaluation of behavioral interventions. Friman and Piazza (2011) define the field of behavioral pediatrics as a branch of medicine that focuses on the relationship between behavior and childhood medical care, particularly the evaluation and treatment of childhood behavior problems presenting themselves within a medical community. One of the main areas of research that ABA has focused on in a medical context is that of toilet training (e.g., Azrin \& Foxx, 1989), including enuresis (e.g., Williams \& Jackson, 2012) and encopresis (e.g., Christophersen \& Rapoff, 1992; Levine, 1982). Additional topics that are frequently researched by behavior analysts that have application to medical treatment and health include pediatric feeding disorders (e.g., Patel, Piazza, Martinez, Volkert, \& Santana, 2002; Piazza et al., 2003; Piazza, Patel, Gulotta, Sevin, \& Layer, 2003) and bedtime problems (e.g., Freeman, 2006). Even in light of these contributions, the physician in the medical field still does not fully embrace the use of such behavioral treatment approaches for reasons including a misunderstanding of the field, behavioral professionals not being readily available, and behavior analytic treatment requiring extensive time and resources (Friman \& Piazza, 2011).

In addition to the large amount of work done in behavioral pediatrics, there are some other areas in which behavior analysts are doing research and clinical treatment that would qualify as behavioral medicine per our definition of environmental manipulation resulting in biological or physiological change. These areas include the reduction of tissue-damaging self-injurious behavior with individuals with developmental disabilities (e.g., McGinnis, Houchins-Juárez, McDaniel, \& Kennedy, 2010; Tiger, Fisher, \& Bouxsein, 2009; Toussaint \& Tiger, 2012), dental hygiene (e.g., Barnoy, Najdowski, Tarbox, Wilke, \& Nollet, 2009; Lang et al., 2013), treatment of problem behavior and skill acquisition in individuals with brain injury (e.g., Fienup, Ahlers, \& Pace, 2011; Guercio, Johnson, \& Dixon, 2012; Travis \& Sturmey, 2010), treatment of Tourette's syndrome (e.g., Capriotti, Brandt, Ricketts, Espil, \& Woods, 2012; Wiskow \& Klatt, 2013), obesity (e.g., Hustyi, Normand, \& Larson, 2011; Hustyi, Normand, Larson, \& Morley, 2012; Shayne, Fogel, Miltenberger, \& Koehler, 2012), smoking cessation (e.g., Dallery \& Raiff, 2011) and inappropriate sexual behavior (e.g., Reyes, Vollmer, \& Hall, 2011a; Reyes, Vollmer, \& Hall, 2011b). According to our analysis, ABA conducted in a medical setting (e.g., medical adherence) would be considered behavioral medicine as long as there is an underlying biological condition of the organism that is somehow altered as a result of compliance with the prescribed regimen.

It would be overzealous to consider that all interventions outside of the use of pharmaceuticals could be considered behavior analytic, meaning that just because an intervention is behavioral does not mean that it qualifies as applied behavior analysis or behavioral medicine. Skill acquisition, for example, is not necessarily behavioral medicine as it is considered normal everyday learning. Additionally, verbal behavior is cultural and distinct and not behavioral medicine. Reduction of problem behavior, where the problem is considered abnormal and/or 
self-injurious, can be considered behavioral medicine if it is specific to a part of the body and not specifically related to cultural behavior (Kantor, 1982).

An intervention in medicine would be considered behavior analytic if it meets all of the following criteria: (1) it is important to society, (2) the physical behavior is observed to be altered, (3) the events that changed the behavior are clearly demonstrated, (4) all aspects and contingencies of the intervention can be clearly identified and described, (5) technology involved can be related back to basic behavioral principles, (6) the intervention must be effective and demonstrative of practical importance, and (7) the behavior change must be durable and appear effective across other environments or behaviors (Baer, Wolf, \& Risley, 1968). Therefore, per our earlier definition, an intervention would be defined as proper behavioral medicine if it met all of the above criteria considered in behavior analysis in addition to the underlying change in the biological organism as a result of its interaction with the environment.

In summation, the science of behavior has a lot to offer the discipline of medicine, and behavioral practices and techniques can be included in the field of medicine, as exemplified in the work of behavioral pediatrics and other disciplines mentioned above in which behavior analysts are conducting research. While the above analysis was not exhaustive, the purpose was to demonstrate that the field of ABA has made significant contributions to $\mathrm{BM}$, but these contributions are sparse. An enhanced relationship between behavior and medicine can be paved through behavioral medicine, if the current relationship between ABA and BM is strengthened.

\section{Progression of Applied Behavior Analysis away from Behavioral Medicine}

During the early formation of the field of behavioral medicine, the influence of the experimental analysis of behavior is evident from the contributing authors as well as the type of research published within the Journal of Behavioral Medicine (JBM). In conducting a review of JBM, it was concluded that early contributing authors included prominent psychologists who identified with behavior theory such as Anthony Biglan, Hank Pennypacker, and Michael Cataldo. However in more recent years, there is no such evidence of contributing behavior analysts. Additionally there has been a notable shift away from single-subject design, a research design methodology primarily utilized by behavior analysts. A review of the articles published in JBM between the years 1978-1982 revealed that $8 \%$ of published used a single-subject design, whereas $0 \%$ of articles published between 2009-2013 employed this type of intervention research.

There are likely multiple reasons as to why ABA is not a primary contributor to the field of BM. Perhaps one of the most widely discussed topics is that within the last 20 years, ABA has largely focused on research and practice in the areas of developmental disabilities and autism. "The conventional wisdom within the field of ABA is that one of the most significant - if not the single most significant - empirically supported success story is ABA-based early intervention for developmental disabilities and childhood autism in particular" (Herbert \& Brandsma, 2002, p.45). This attention to ABA as a treatment method for autism began in the 1960s with Ivar Lovaas and his studies on treatment of behaviors associated with autism (Smith \& Eikeseth, 2011). Since that time, prevalence of autism has been on the rise (Center for Disease Control and Prevention, 2014) and ABA has constructed an entire body of research around its treatment (Fielding et al., 2013).

Progressively, more professionals in the behavior analytic community are expressing concern with regard to the science losing its identity as a result of the trend toward research and 
practice in autism and disabilities (Fielding et al., 2013). Twenty years ago, there was a notable increase in JABA publications seen in developmental disabilities (Northup, Vollmer, \& Serrett, 1993) and over 10 years ago, Hayes (2001) suggested that the field of ABA is slowly becoming a subfield of developmental disabilities. While research in autism and other developmental disabilities is crucial and ABA's contributions in these topic areas are vital, these trends in research and notoriety within the field put the science of ABA at risk for getting lost among other areas for potential contributions, such as behavioral medicine. With regard to autism treatment, Dillenburger and Keenan (2009) warn that learning certain techniques such as discrete trial training is not the same as learning the entire science of ABA, which can be applied to help people in a wide variety of circumstances. A main concern for the prosperity of behavior analysis is, "the growing focus of applied behavior analysis on autism spectrum disorders and little else" (Poling, 2010, p. 7).

With this increased interest in autism, the focus on autism training became predominant. Larger numbers of master's level clinicians in ABA were in demand and clinical training programs also began to focus on autism. In 2011, a survey of Board Certified Behavior Analysts (BCBA) was conducted by the Behavior Analysis Certification Board (BACB) on the primary client population served (BACB Online Newsletter, 2011). Results of the survey data suggested that $54.48 \%$ of BCBA respondents supported individuals with autism, $23.50 \%$ supported individuals with developmental disabilities whereas only $0.19 \%$ supported clients in the health field and $0.26 \%$ supported people struggling with drug and alcohol abuse. The shift in the field was so apparent that the BACB engaged in discussions of issuing a separate credential for practitioners of autism (BACB Online Newsletter, 2009). Additionally, in 2007, an entire conference dedicated to topics and research in autism was launched by ABAI and has been a successful yearly conference ever since. It is probable that this shift toward training and research on autism has impacted the productivity of behavior analysts in other topic areas.

There are two economic contingencies that may have contributed to ABA's shift toward research on autism and developmental disabilities, as opposed to other areas of scientific inquiry. First and foremost, between the years of 1998 and 2006, funding for autism research increased $15 \%$ each year, and these funding priorities focused more on clinical treatments and translational research as opposed to basic science (Singh, Illes, Lazzeroni, \& Hallmayer, 2009). An additional economic contingency that may have influenced this shift includes private pay and insurance dollars available for autism treatment and the field's interest in supporting and producing more graduate level clinicians to treat autism and other behavior disorders.

To summarize, the focus on autism and developmental disabilities has diverted behavior analysts from participating in research in other topic areas, such as behavioral medicine. It is a very real concern within the field that the research and practice is being pigeonholed into almost exclusively autism and development disabilities. Seen in both research and practice, the interest in autism has significantly grown the field of behavior analysis and gained recognition for doing so, however if the science is to flourish, other areas of research should be pursued.

\section{Re-Integration of Behavioral Medicine with Applied Behavior Analysis}

Despite the currently distant relationship, from the time of BM's inception in the late 1970s, ABA practitioners and researchers have been interested in contributing to the field. Numerous scholars in ABA have suggested that behavior analysts should be involved in behavioral medicine (e.g., Ator, 1986; Blum \& Friman, 2000; Fawcett, 1985; Fraley, 1981; Glenn, 1993; 
Pennypacker, 1981) and have even gone as far as to recommend behavioral medicine as an emphasis for master's degree programs in ABA (e.g., Ellis \& Glenn, 1995; Hopkins \& Moore, 1993; Moore \& Shook, 2001). Based on our research, few behavior analysts are still addressing this collaboration today.

Historically, the early formation of the field of BM included behavior science as a main contributor (Schwartz \& Weiss, 1978b) and gave great consideration to ABA's principles. To demonstrate the shift in use of principles in the early years of the field as compared to the current years, the authors conducted a review of the research designs used in the first 5 years and the last 5 years of the Journal of Behavioral Medicine. While there were only 14 articles in the early years of the Journal of Behavioral Medicine utilizing a single-subject research design, a reduction to zero in the most recent years of the journal indicates a shift away from singlesubject research methodology. Additionally, a review of the last 5 years of JBM shows that the contributors and researchers in the field are primarily medical practitioners and psychologists. Behavior analysts took an interest in the field during BM's foundation and formulation (Fuqua, 1980), but given the recent surge in interest in autism and other developmental disabilities, the collaborative and influential efforts have waned. While the two disciplines have similar purposes and there has been some early collaboration between BM and ABA (e.g. Biglan et al., 1987; Biglan, Noell, Ochs, Smolkowski, \& Metzler, 1995; Cataldo, Bird, \& Cunningham, 1978; Stephenson, Adams, Hall, \& Pennypacker, 1979), there has been an obvious progression in ABA away from BM. However there is potential benefit that a behavioral approach can bring to the field of BM.

In order to address the changes that need to occur, the challenges to integration must be considered. To begin, ABA is a newer science and perhaps not as widely recognized for its contributions to health care as are mainstream psychology or medicine, especially considering that so much of the research in $\mathrm{ABA}$ is conducted with people with extreme psychiatric conditions and developmental disabilities. Skinner (1976) had envisioned that ABA would be relevant and applicable to virtually all human behavior and thus far, his vision has not yet been realized, largely as a result of the narrow scope of the majority of the research being conducted. Additionally, ABA is quite isolated in its publications and presentations, with researchers publishing primarily in behavior analytic journals and presenting at behavior analytic conferences, which inhibits awareness and dissemination to other fields. Finally, degree programs in $\mathrm{ABA}$ are still being formulated and accredited and have historically existed mostly at the master's and doctoral level, with less opportunity for student exposure prior to a post baccalaureate education. This limited exposure hinders the dissemination of behavior analytic theories in undergraduate education and further isolates the field to those who happened upon behavior analysis at a specific university or with a specific clinical population (e.g., autism). To propose some solutions to these barriers, we suggest several strategies that likely would result in a greater collaboration between $\mathrm{ABA}$ and $\mathrm{BM}$.

Whereas there are several behavioral researchers that publish outside of the behavioral journals (e.g., Friman, Handwerk, Swearer, McGinnis, \& Warzak, 1998; Raiff, Faix, Turuturici, \& Dallery, 2010), applied behavior analysts wanting to influence health care should be conducting research with medical practitioners, publishing this work in medical journals, and presenting their research at medical conferences, including the Conference of the Society of Behavioral Medicine. While these recommendations might seem lofty, and likely are, there may be ways to collaborate on research in BM in order to reach the medical community. "To achieve mainstream status, behavior analysis needs to compromise neither its principles nor its practices. 
A much more practical and efficient way to enter the mainstream is to integrate with a field that is already there," (Friman, 2010, p. 20). Given that there was a preexisting history with behavior science and behavioral medicine, it seems like an obvious opportunity for such partnership. Furthermore, it may behoove behavior analysts to use common terminology in publishing outside of BA journals, while still maintaining the integrity of the procedures and principles (Friman, 2010). It is also important to engage in flexibility with regard to the type of research design selected when collaborating with researchers in other disciplines who may be unfamiliar with or not value the utility of single-subject research.

Perhaps most important to dissemination, recognition, and collaboration of ABA and BM is diversification of research. The contribution of behavior analysis to the field of autism and developmental disabilities is profound and undeniable, and should not be minimized. However, in order to achieve Skinner's early vision of mainstream prominence, a demonstration of mainstream relevance is needed, therefore mandating a need for ABA to diversify areas of contribution (Friman, 2010). Some of the work in ABA could be categorized as behavioral medicine, especially given our analysis of environmental conditions being used to address biological functions of the organism. However, in reviewing behavior analytic journals, it was noticed that only a handful of researchers in the field of ABA were classifying their work as behavioral medicine. If $\mathrm{ABA}$ research with relation to $\mathrm{BM}$ were labeled in the key words, it would be more accessible to the medical practitioners via internet search and conference attendance. Finally, Friman and Piazza (2011) make some excellent recommendations specific to ABA and behavioral pediatrics, including the advice to collaborate with practitioners on clinical cases and make a case for third-party payers to require documentation of treatment outcomes and data-based decision making.

Additionally, ABA research, clinical practices and theory should be made more regularly available to high school and undergraduate students, through development of a general introduction to behavior analysis courses and course sequences specific to that of a baccalaureate level clinician. In 2004, Madden and colleagues surveyed the undergraduate psychology programs at 20 randomly selected public universities. They found that only two of the schools offered classes on both applied behavior analysis and on the experimental analysis of behavior. Two of the schools did not require any courses on applied or basic behavior analysis, while requiring two courses in cognitive, developmental or personality psychology. Their conclusion was that a majority of students at these universities would graduate with a degree in psychology without ever being exposed to behavior analysis. In their paper, they describe the process they went through to create an undergraduate emphasis in behavior analysis at the University of Wisconsin, Eau Clair, including paid, supervised internships, leading to being qualified for the BCaBA certification upon graduation (Madden, Klatt, Jewett, \& Morse, 2004). Other schools might consult this research and start similar programs. In doing so, behavior analysis will hopefully become a more mainstream science and regularly adopted by other health care professions in favor in integrated healthcare.

Given that there are many benefits to ABA by collaborating with and contributing to BM, it is necessary to include the parallel discussion of how BM can benefit from ABA. The integration of ABA with BM actually extends the effectiveness of BM, therefore benefitting not only the field, but society and medical practices, as a whole. Behavioral problems that may initially appear trivial in the medical community, especially in pediatrics, may actually represent problems that may have long term side effects for the individual, the individual's family, and the potential need for increased resources and services in the future (Friman, 2010). The 
collaboration of behavior analysts with physicians, through the avenue of behavioral medicine, will help medical practitioners better understand the relationship between biology and behavior and likely impact the practitioners' approach to health care, prevention, and treatment.

Behavior analysts frequently use single-subject research designs in their approach to research and treatment evaluation (Johnston \& Pennypacker, 2008). There are many benefits to single-subject research including intensely studying the process of change over time as well as determining if an intervention works for an individual person, of which all cases in health possess a certain uniqueness. Perhaps most notably and relevant to this paper, single-subject designs are useful in gathering pilot data in the early stages of research to help inform group designs (Franklin, Allison, \& Gorman, 2014).

Whereas both single-subject and group-based designs have their benefits and limitations, a vast majority of the current studies in BM make use of experimental group designs exclusively, relying heavily on use of the randomized clinical trial (RCT). RCTs, a widely accepted experimental design, have immense and positive implications for research funding and best practice treatment protocols for the average patient, especially in the domain of medicine (Franklin, Allison, \& Gorman, 2014). However, two major limitations of RCTs include the inability to generalize the interventions to an individual within the group and the overreliance upon indirect and subjective assessment measures in collecting data (Smith, 2012). RCTs often examine multiple components or procedures at once, which is valuable to the scientist; however in a science to practice model, it makes it difficult to analyze which components are needed (Birnbrauer, 1979). Additionally, RCTs focus on the average change of groups as opposed to the change seen in an individual participant (Sidman, 1960; Smith, 2012). As a result of such limitations, researchers such as Follette (1995) have concluded that RCT research strategies have been unsuccessful in providing clear data for developing a set of standards useful in clinical practice.

Whereas RCTs are quite useful for observing large-scale impact, it is both necessary and preferable to conduct individual treatment procedures on individual behaviors using singlesubject design (Johnston \& Pennypacker, 2008: Sidman, 1960). ABA can assist clinicians in behavioral medicine through implementation of clinical treatment evaluation using single-subject research methodology and development of useful sets of clinical standards resulting from such research designs. To strengthen the usability of BM research in practice, researchers may begin their research through single-subject designs followed by a RCT. The combination of strengths within these two research designs will inform policy, achieve funding, and enhance best treatment practices.

\section{An Interdisciplinary Collaboration between Biomedical Science and Behaviorism}

Kantor (1963) said that the goal of a science is orientation to the world. His position was that a scientific enterprise is composed of the characteristics of seriousness and originality, where originality is based on the idea that science accumulates and changes over time. Kantor also explained that there are four generalized procedures that each science makes use of in its work: direct observation, instrumental observation, transforming contacts, and remote observation. Direct observation concerns the immediate contact with things and events, such that they can be observed and manipulated. Instrumental observation concerns the measurement of things and events for purposes of scientific record. Transforming contacts concerns the manipulation of things and events that may not necessarily occur in nature. Finally, remote observation, as 
Kantor described it, is the most subtle type of science in that it is indirect and inferential. Behavior science significantly lends to the direct observational component of Kantor's definition, whereas biomedicine relies heavily on transforming contacts as well as instrumental and indirect observation. When combining approaches, behavioral medicine, per our definition, provides a very complete science and integrated model of health care.

True interdisciplinary work, however, faces many challenges given the distinctive world views of the differing disciplines (Pepper, 1970). For example, behavior scientists are likely to identify with the world hypothesis or view of contextualism, the philosophy of ongoing change and systematic working in context, whereas biologists may identify with mechanism, where the whole organism is reducible to its parts, and developmental psychologists may identify with organicism, where the parts are only meaningful in relation to the whole and organisms are assumed to move through specific stages of development based on their biological structures (Hayes, Hayes, \& Reese, 1988). While some world views are more amenable to the philosophies, theories, and underlying assumptions of other world views, it is nearly impossible to change someone's world view, and conflict can arise from eclecticism in this domain (Pepper, 1970). Given that BM is currently comprised of many different scientific disciplines, the current practitioner or researcher of BM may not only be considered interdisciplinary, but eclectic by subscribing to multiple world hypotheses. Given the many contributing subjects in the field of behavior medicine, naturally there are eclectic word views. By removing some of this eclecticism, the field of behavioral medicine may likely be able to further develop its theories, philosophies, and scientific assumptions.

In efforts to integrate the behaviorism and medicine, it is important to consider some implications for training clinicians in BM. There are currently very few universities that offer degree or sequence programs in behavioral medicine. The courses offered in these degree and training programs should focus on both behavior science, drawing materials largely from ABA, as well as biomedical treatment. In order to conduct environmental manipulations to change behaviors that have an effect on a biological condition of the body, a thorough understanding of both biomedicine and behavior analysis is necessary.

Perhaps the most important implication of collaboration between ABA and BM is the future of behavioral health care. Biglan and Glenn (2012) explained that a main focus of contemporary public health efforts is non-infectious disease, such as cancer and obesity, wherein behavior is a major contributor to these diseases. An increased collaboration between ABA and BM will likely result in the ability to provide cost-effective data to support various behavioral treatments in health care. Treatment evaluation will be able to make use of single-subject research, which will be practical for development of treatment programs (Hayes, Barlow, \& Nelson-Gray, 1999).

Ideally, a practitioner of behavioral medicine would be a scientist practitioner. Hayes and colleagues (Hayes, Barlow, \& Nelson-Gray, 1999) explained the roles of the scientist practitioner: (1) consumer of new research, especially new treatments; (2) evaluator of their own empirically based interventions; and (3) reporter of their evaluation data to the scientific community. In the age of managed health care, the scientist practitioner model is ideal for maintaining the development of evidence based treatment programs, administration of these programs, and the evaluation of behavioral health care programs. In this model, the doctorallevel practitioner will be able to practice, oversee the implementation of practices by more affordable masters-level clinicians, and report their findings to third-party payment providers with the goal of providing the most cost effective and efficient treatment programs (Hayes et al, 1999). 


\section{APPLIED BEHAVIOR ANALYSIS AND BEHAVIORAL MEDICINE}

The proposed collaborations would increase the likelihood that the fields of BM and the ABA would make progress toward producing useful and rigorous experimental research, utilizing both single subject and RCT research designs. They would provide effective and empirically demonstrated treatment packages to medical practitioners, and produce clinicians of behavioral medicine with background knowledge in both biomedical and behavioral science. Most importantly, ABA, in conjunction with BM, would be able to produce effective behavior change procedures in relation to the prevention and treatment of disease and other conditions of the human body, further extending Skinner's vision of applied behavior analysis as applicable to all human behavior.

\section{References}

Agras, W. S. (1982). Behavioral medicine in the 1980s: Nonrandom connections. Journal of Consulting and Clinical Psychology, 50, 797-803. http://dx.doi.org/10.1037/0022-006X.50.6.797

Agras, W. S. (2001). The development of behavioral medicine. In A History of the Behavioral Therapties:

Founders' Personal Histories, Context Press: Reno, NV.

Association for Behavior Analysis International. (n.d.). Retrieved from www.abainternational.org

Ator, N. A. (1986). Behavioral biology. The Behavior Analyst, 9(1), 123-125.

Azrin, N., \& Foxx, R. M. (1989). Toilet training in less than a day. Simon and Schuster.

Baer, D. M., Wolf, M. M., \& Risley, T. R. (1968). Some current dimensions of applied behavior analysis. Journal of Applied Behavior Analysis, 1(1), 91-97. http://dx.doi.org/10.1901/jaba.1968.1-91

Barnoy, E. L., Najdowski, A. C., Tarbox, J., Wilke, A. E., \& Nollet, M. D. (2009). Evaluation of a multicomponent intervention for diurnal bruxism in a young child with autism. Journal of Applied Behavior Analysis, 42(4), 845-848. http://dx.doi.org/10.1901/jaba.2009.42-845

Behavior Analysis Certification Board (2009). Online newsletter. Retrieved from: http://www.bacb.com/newsletter/BACB_Newsletter_02-09.pdf

Behavior Analysis Certification Board (2011). Online newsletter. Retrieved from: http://www.bacb.com/newsletter/BACB_Newsletter_05_2011.pdf

Biglan, A., Glasgow, R., Ary, D., Thompson, R., Severson, H., Lichtenstein, E., Weissman, W., Faller, C., \& Gallison, C. (1987). How generalizable are the effects of smoking prevention programs? Refusal skills training and parent messages in a teacher-administered program. Journal of Behavioral Medicine, 10(6), 613-628. http://dx.doi.org/10.1007/BF00846658

Biglan, A. \& Glenn, S. S. (2012). Toward prosocial behavior and environments: Behavioral and cultural contingencies in a public health framework. In APA Handbook of Behavior Analysis (Volume 2, pp. 255-276). Washington DC: American Psychological Association.

Biglan, A., Noell, J., Ochs, L., Smolkowski, K., \& Metzler, C. (1995). Does sexual coercion play a role in the highrisk sexual behavior of adolescent and young adult women? Journal of Behavioral Medicine, 18(6), 549-568. http://dx.doi.org/10.1007/BF01857895

Birnbrauer, J. S. (1979). Applied behavior analysis, service and the acquisition of knowledge. The Behavior Analyst, 2(1), 15.

Blum, N., \& Friman, P.C. (2000). Behavioral pediatrics: The confluence of applied behavior analysis and pediatric medicine. In J. Carr and J. Austin (Eds.) Handbook of applied behavior analysis, (pp. 161-186). Reno, NV: Context Press.

Capriotti, M. R., Brandt, B. C., Ricketts, E. J., Espil, F. M., \& Woods, D. W. (2012). Comparing the effects of differential reinforcement of other behavior and response-cost contingencies on tics in youth with Tourette syndrome. Journal of Applied Behavior Analysis, 45(2), 251-263. http://dx.doi.org/10.1901/jaba.2012.45-251

Cataldo, M. F., Bird, B. L., \& Cunningham, C. E. (1978). Experimental analysis of EMG feedback in treating cerebral palsy. Journal of Behavioral Medicine, 1(3), 311-322. http://dx.doi.org/10.1007/BF00846682

Center for Disease Control and Prevention. CDC estimates 1 in 68 children has been identified with autism spectrum disorder. Retrieved April 1, 2014, from http://www.cdc.gov/media/releases/2014/p0327-autism-spectrumdisorder.html.

Christophersen, E.R. \& Rapoff, M.A. (1992). Toileting problems of children. In C.E. Walker \& M.C. Roberts (Eds.), Handbook of clinical child psychology (pp. 593-615). New York: Wiley \& Sons. 


\section{GREENWALD, ROOSE, \& WILLIAMS}

Cooper J.O, Heron T.E, \& Heward W.L. (2007). Applied behavior analysis (2nd ed.). Upper Saddle River, NJ: Pearson.

Dallery, J., \& Raiff, B. R. (2011). Contingency management in the 21 st century: technological innovations to promote smoking cessation. Substance Use \& Misuse, 46(1), 10-22. http://dx.doi.org/10.3109/10826084.2011.521067

Dillenburger, K., \& Keenan, M. (2009). None of the As in ABA stand for autism: Dispelling the myths. Journal of Intellectual \& Developmental Disability, 34(2), 193-195. http://dx.doi.org/10.1080/13668250902845244

Ellis, J., \& Glenn, S. S. (1995). Behavior-analytic repertoires: Where will they come from and how can they be maintained? The Behavior Analyst, 18(2), 285-292.

Fawcett, S. B. (1985). On differentiation in applied behavior analysis. The Behavior Analyst, 8(2), 143-150.

Fielding, C., Lowdermilk, J., Lanier, L. L., Fannin, A. G., Schakade, J. L., Rose, C. A., \& Simpson, C. G. (2013). Applied behavior analysis: Current myths in public education. Journal of the American Academy of Special Education Professionals, Spring/Summer, 83-97.

Fienup, D. M., Ahlers, A. A., \& Pace, G. (2011). Preference for fluent versus disfluent work schedules. Journal of Applied Behavior Analysis, 44(4), 847-858. http://dx.doi.org/10.1901/jaba.2011.44-847

Follette, W. C. (1995). Correcting methodological weaknesses in the knowledge base used to derive practice standards. Chapter in S. C. Hayes, V. M. Follette, R. M. Dawes, and K. E. Grady (Eds.) Scientific Standards of Psychological Practice: Issues and Recommendations. Reno, NV: Context Press, 229-247.

Fraley, L. E. (1981). The spread of behavior analysis to the applied fields. The Behavior Analyst, 4(1), 33-41.

Franklin, R. D., Allison, D. B., \& Gorman, B. S. (Eds.). (2014). Design and analysis of single-case research. Psychology Press.

Freeman, K. A. (2006). Treating bedtime resistance with the bedtime pass: A systematic replication and component analysis with 3-year-olds. Journal of Applied Behavior Analysis, 39(4), 423-428. http://dx.doi.org/10.1901/jaba.2006.34-05

Friman, P. C. (2010). Come on in, the water is fine: Achieving mainstream relevance through integration with primary medical care. The Behavior Analyst, 33(1), 19.

Friman, P. C., Handwerk, M. L., Swearer, S. M., McGinnis, C., \& Warzak, W. J. (1998). Do children with primary nocturnal enuresis have clinically significant behavior problems? Archives of Pediatrics and Adolescent Medicine, 152(6), 537-539. http://dx.doi.org/10.1001/archpedi.152.6.537

Friman, P. C., \& Piazza, C. (2011). Behavioral pediatrics. In W. Fisher, C. Piazza, \& H. S. Roane (Eds., pp. 433450), Handbook of Applied Behavior Analysis. New York: Guilford.

Fuqua, R. W. (1980). The promise of behavioral medicine: A review of Pomerleau and Brady's behavioral medicine: Theory and practice. Journal of Behavioral Medicine, 3(2), 49-56.

Gellman, M., \& Turner, J. R. (Eds.). (2013). Encyclopedia of behavioral medicine (Vols. 1-4). New York, NY: Springer New York. http://dx.doi.org/10.1007/978-1-4419-1005-9

Glenn, S. S. (1993). Windows on the $21^{\text {st }}$ century. The Behavior Analyst, 16(2), 133-151.

Guercio, J. M., Johnson, T., \& Dixon, M. R. (2012). Behavioral treatment for pathological gambling in persons with acquired brain injury. Journal of Applied Behavior Analysis, 45(3), 485-495. http://dx.doi.org/10.1901/jaba.2012.45-485

Hayes, S. C. (2001). The greatest dangers facing behavior analysis today. The Behavior Analyst Today, 2(2), 61-63. http://dx.doi.org/10.1037/h0099914

Hayes, S. C., Barlow, D. H., \& Nelson-Gray, R. O. (1999). The scientist practitioner: Research and accountability in the age of managed care. Allyon and Bacon: Needham Heights, MA.

Hayes, S. C., Hayes, L. J., \& Reese, H. W. (1988). Finding the philosophical core: A review of Stephen C. Pepper's World Hypotheses: A Study in Evidence. Journal of the Experimental Analysis of Behavior, 50(1), 97-111. http://dx.doi.org/10.1901/jeab.1988.50-97

Herbert, J.D. \& Brandsma, L. L. (2002). Applied behavior analysis for childhood autism: Does the emperor have clothes? The Behavior Analyst Today, 3(1), 45-50. http://dx.doi.org/10.1037/h0099958

Hopkins, B. L. \& Moore, J. (1993). ABA accreditation of graduate programs of study. The Behavior Analyst, 16(1), $117-121$.

Hustyi, K. M., Normand, M. P., \& Larson, T. A. (2011). Behavioral assessment of physical activity in obese preschool children. Journal of Applied Behavior Analysis, 44(3), 635-639. http://dx.doi.org/10.1901/jaba.2011.44-635 


\section{APPLIED BEHAVIOR ANALYSIS AND BEHAVIORAL MEDICINE}

Hustyi, K. M., Normand, M. P., Larson, T. A., \& Morley, A. J. (2012). The effect of outdoor activity context on physical activity in preschool children. Journal of Applied Behavior Analysis, 45(2), 401-405. http://dx.doi.org/10.1901/jaba.2012.45-401

International Society of Behavioral Medicine. www.isbm.info. Accessed March 1, 2015.

Johnston, J. M., Pennypacker, H. S. (2008). Strategies and tactics of behavioral research, third edition. New York, NY: Routledge

Kangas, B. D. \& Vaidya, M. (2007). Trends in presentations at the annual conference of the Association for Behavior Analysis. The Behavior Analyst, 30(2), 117-131.

Kantor, J. R. (1963). The scientific evolution of psychology (Vol. I). Chicago, IL: Principia Press. http://dx.doi.org/10.1037/11183-000

Kantor, J. R. (1982). Cultural psychology. Chicago, IL: Principia Press.

Lang, R., Davenport, K., Britt, C., Ninci, J., Garner, J., \& Moore, M. (2013). Functional analysis and treatment of diurnal bruxism. Journal of Applied Behavior Analysis, 46(1), 322-327. http://dx.doi.org/10.1002/jaba.5

Levine, M. D. (1982). Encopresis: Its potentiation, evaluation and alleviation. Pediatric Clinics of North America, 29(2), 315-330.

Madden, G. J., Klatt, K. P., Jewett, D. C., \& Morse, L. A. (2004). A forgotten resource critical to the future of behavior analysis: Undergraduate psychology majors. The Behavior Analyst, 27(1), 33-41.

McGinnis, M. A., Houchins-Juárez, N., McDaniel, J. L., \& Kennedy, C. H. (2010). Abolishing and establishing operation analyses of social attention as positive reinforcement for problem behavior. Journal of Applied Behavior Analysis, 43(1), 119-123. http://dx.doi.org/10.1901/jaba.2010.43-119

Moore, J. \& Shook, G. L. (2001). Certification, accreditation, and quality control in behavior analysis. The Behavior Analyst, 24(1), 45-55.

Northup, J., Vollmer, T. R., \& Serrett, K. (1993). Publication trends in 25 years of the journal of applied behavior analysis. Journal of Applied Behavior Analysis, 26(4), 527-537. http://dx.doi.org/10.1901/jaba.1993.26-527

Patel, M. R., Piazza, C. C., Martinez, C. J., Volkert, V. M., \& Christine, M. S. (2002). An evaluation of two differential reinforcement procedures with escape extinction to treat food refusal. Journal of Applied Behavior Analysis, 35(4), 363-374. http://dx.doi.org/10.1901/jaba.2002.35-363

Pepper, S. C. (1970). World hypotheses. Los Angeles, CA: California Press.

Pennypacker, H. S. (1981). On terms: On behavioral analysis. The Behavior Analyst, 4(2), 159-161.

Piazza, C. C., Fisher, W. W., Brown, K. A., Shore, B. A., Patel, M. R., Katz, R. M., Sevin, B. M., Gulotta, C. S., \& Blakely-Smith, A. (2003). Functional analysis of inappropriate mealtime behaviors. Journal of Applied Behavior Analysis, 36(2), 187-204. http://dx.doi.org/10.1901/jaba.2003.36-187

Piazza, C. C., Patel, M. R., Gulotta, C. S., Sevin, B. M., \& Layer, S. A. (2003). On the relative contributions of positive reinforcement and escape extinction in the treatment of food refusal. Journal of Applied Behavior Analysis, 36(3), 309-324. http://dx.doi.org/10.1901/jaba.2003.36-309

Poling, A. (2010). Looking to the future: Will behavior analysis survive and prosper? The Behavior Analyst, 33(1), 7-17.

Raiff, B.R., Faix, C., Turturici, M., \& Dallery, J. (2010). Breath carbon monoxide output is affected by speed of emptying the lungs: Implications for laboratory and smoking cessation research. Nicotine and Tobacco Research, 12(8), 834-838. http://dx.doi.org/10.1093/ntr/ntq090

Reyes, J. R., Vollmer, T. R., \& Hall, A. (2011a). Replications and extensions in arousal assessment for sex offenders with developmental disabilities. Journal of Applied Behavior Analysis, 44(2), 369-373. http://dx.doi.org/10.1901/jaba.2011.44-369

Reyes, J. R., Vollmer, T. R., \& Hall, A. (2011b). The influence of presession factors in the assessment of deviant arousal. Journal of Applied Behavior Analysis, 44(4), 707-717. http://dx.doi.org/10.1901/jaba.2011.44-707

Schwartz, G. E. \& Weiss, S. M. (1978a). Behavioral medicine revisited: An amended definition. Journal of Behavioral Medicine, 1(3), 249-250. http://dx.doi.org/10.1007/BF00846677

Schwartz, G. E. \& Weiss, S. M. (1978b). Yale conference on behavioral medicine: A proposed definition and statement of goals. Journal of Behavioral Medicine, 1(1), 3-12. http://dx.doi.org/10.1007/BF00846582

Shayne, R. K., Fogel, V. A., Miltenberger, R. G., \& Koehler, S. (2012). The effects of exergaming on physical activity in a third-grade physical education class. Journal of Applied Behavior Analysis, 45(1), 211-215. http://dx.doi.org/10.1901/jaba.2012.45-211

Sidman, M. (1960). Tactics of scientific research: Evaluating experimental data in psychology. New York, NY: Basic Books. 


\section{GREENWALD, ROOSE, \& WILLIAMS}

Singh, J., Illes, J., Lazzeroni, L., \& Hallmayer, J. (2009). Trends in US Autism Research Funding. Journal of Autism and Developmental Disorders, 39(5), 788-795. http://dx.doi.org/10.1007/s10803-008-0685-0

Skinner, B. F. (1976). About behaviorism. New York, NY: Vintage.

Smith, T. (2012). Evolution of research on interventions for individuals with autism spectrum disorder: Implications for behavior analysts. The Behavior Analyst, 35(1), 101-113.

Smith, T., Eikeseth, S. (2011). O. Ivar Lovaas: Pioneer of applied behavior analysis and intervention for children with autism. Journal of Autism and Developmental Disorders, 41, 375-378. http://dx.doi.org/10.1007/s10803$\underline{010-1162-0}$

Society of Behavioral Medicine. (n.d.) Retrieved from www.sbm.org.

Stephenson, H. S., Adams, C. K., Hall, D. C., \& Pennypacker, H. S. (1979). Effects of certain training parameters on detection of simulated breast cancer. Journal of Behavioral Medicine, 2(3), 239-250. http://dx.doi.org/10.1007/BF00844921

Tiger, J. H., Fisher, W. W., \& Bouxsein, K. J. (2009). Therapist- and self-monitored DRO contingencies as a treatment for the self-injurious skin picking of a young man with Asperger Syndrome. Journal of Applied Behavior Analysis, 42(2), 315-319. http://dx.doi.org/10.1901/jaba.2009.42-315

Toussaint, K. A., \& Tiger, J. H. (2012). Reducing covert self-injurious behavior maintained by automatic reinforcement through a variable momentary DRO procedure. Journal of Applied Behavior Analysis, 45(1), 179-184. http://dx.doi.org/10.1901/jaba.2012.45-179

Travis, R., \& Sturmey, P. (2010). Functional analysis and treatment of the delusional statements of a man with multiple disabilities: A four-year follow-up. Journal of Applied Behavior Analysis, 43(4), 745-749. http://dx.doi.org/10.1901/jaba.2010.43-745

Williams, W. L., \& Jackson, M. (2012). Enuresis. In P. Sturmey and M. Hersen (Eds.) Handbook of Evidence Based Practice in Clinical Psychology, Volume 1: Child and Adolescent Disorders, New York, NY: Wiley. http://dx.doi.org/10.1002/9781118156391.ebcp001016

Wiskow, K. M. \& Klatt, K. P. (2013). The effects of awareness training on tics in a young boy with Tourette syndrome, Asperger syndrome, and attention deficit hyperactivity disorder. Journal of Applied Behavior Analysis, 46(3), 695-698. http://dx.doi.org/10.1002/jaba.59 